\title{
CALIDAD DE LA LECHE Y MASTITIS SUBCLÍNICA EN ESTABLOS DE LA PROVINCIA DE HUAURA, LIMA
}

\author{
Milk Quality and Subclinical mastitis in Dairy Herds in the Province of \\ Huaura, Lima-Peru
}

\author{
Carlomagno Velásquez $\mathbf{V}_{\bullet}^{1,2}$, Jaime Vega $\mathbf{~}^{1}$
}

\section{RESUMEN}

El presente estudio se realizó en la provincia de Huaura, región Lima-Provincias, entre 2009 y 2010, y tuvo por objetivo determinar la calidad de leche mediante el Recuento de Células Somáticas (RCS), en tanques de leche de tres establos y cuatro asociaciones de pequeños ganaderos, en dos épocas del año. Asimismo, evaluar la mastitis subclínica en 32 establos (2100 vacas), utilizando la prueba de California Mastitis Test (CMT), teniendo en consideración el número de parto, tamaño del establo y momento de lactancia. No hubo diferencia estadística entre los RCS de establos (755.4 \pm 46.9 × $10^{3}$ células/ $\mathrm{ml}$ ) con los valores de las asociaciones de pequeños ganaderos (752.1 \pm 41.1 x $10^{3}$ células/ $\mathrm{ml})$; sin embargo hubo diferencias entre establos $(\mathrm{p}<0.05)$. El RCS en el verano (957.1 \pm 54.1 x $10^{3}$ células $/ \mathrm{ml}$ ) fue superior al obtenido en el invierno ( $550.3 \pm 35.5$ x $10^{3}$ células $\left./ \mathrm{ml}\right)$ $(\mathrm{p}<0.05)$. Una mayor proporción de cuartos afectados con mastitis subclínica se observó en los establos medianos y grandes en comparación a los pequeños (52.6 y 49.9\% vs $29.8 \%$, respectivamente) $(\mathrm{p}<0.05)$, en vacas con más de dos partos en comparación a vacas con 1 y 2 partos (40.8, 32.8 y $24.8 \%$, respectivamente) $(\mathrm{p}<0.05)$, y en vacas al final de lactancia en comparación a las de lactancia media e inicial (40.3, 38.2 y 23.2\%, respectivamente) $(\mathrm{p}<0.05)$. La leche proveniente de los establos y asociaciones de ganaderos de la zona de Huaura no cumple las normas técnicas de calidad de la legislación peruana en términos de RCS. La mastitis subclínica estuvo asociada al tamaño del establo, número de parto y momento de lactancia.

Palabras clave: mastitis subclínica, calidad de leche, células somáticas, estación del año

\section{Abstract}

This research was conducted in the province of Huaura, Lima-Peru in 2009-2010 to determine the quality of milk through Somatic Cell Count (SCC) in milk tanks of three dairy herds and four small farmer associations in two seasons of the year, and to assess subclinical mastitis by the California Mastitis Test (CMT) in 32 farms (2100 cows), considering parity, herd size and lactation phase. No statistical difference was found

\footnotetext{
${ }^{1}$ Escuela Académico Profesional de Zootecnia (EAPZ), Facultad de Ciencias Agrarias e Industria Alimentarias, Universidad Nacional José Faustino Sánchez Carrión (UNJFSC), Huacho, Perú

${ }^{2}$ E-mail: cvvergara11@hotmail.com
} 
between large dairy herds ( $755.4 \pm 46.9 \times 10^{3}$ cells $\left./ \mathrm{ml}\right)$ and farmer associations (752.1 \pm 41.1 x $10^{3}$ cells $\left./ \mathrm{ml}\right)$; however, there were differences between farms $(\mathrm{p}<0.05)$. The RCS in summer (957.1 $\pm 54.1 \times 10^{3}$ cells $\left./ \mathrm{ml}\right)$ was higher than in winter $\left(550.3 \pm 35.5 \times 10^{3}\right.$ cells $\left./ \mathrm{ml}\right)$ $(\mathrm{p}<0.05)$. A greater proportion of CMT positive quarters were observed in medium and large herds compared to small herds ( 52.6 and $49.9 \%$ vs $29.8 \%$ respectively) ( $<<0.05$ ), in cows with $>2$ parities in comparison to $1^{\text {st }}$ and $2^{\text {nd }}$ calvers (40.8 vs 32.8 and $24.8 \%$ respectively) ( $\mathrm{p}<0.05$ ), and in cows in late lactation compared to mid and early lactation ( 40.3 vs 38.2, and $23.2 \%$ respectively) $(\mathrm{p}<0.05$ ). Milk from Huaura dairy farms associations does not meet the Peruvian quality standards in terms of RCS. Subclinical mastitis was associated with herd size, parity, and time of lactation.

Key words: subclinical mastitis, milk quality, somatic cell, season of the year

\section{INTRODUCCIÓN}

La producción de leche en el Perú ha tenido un crecimiento sostenido de $6.7 \%$ anual en los últimos 15 años. De los 830146 TM de leche producidos en 1994 se ha incrementado a 1660700 TM en 2009 (MINAG, 2010); sin embargo, la mayor producción no ha estado necesariamente acompañada de una mejora en su calidad.

La mastitis es uno de los principales problemas sanitarios que afecta la calidad de la leche; además de causar una disminución de la producción y un incremento en los gastos por tratamiento. La mastitis es responsable del $12 \%$ de descartes de vacas de los establos de la cuenca de Lima (Orrego et al., 2003).

La leche proveniente de cuartos afectados con mastitis subclínica presenta un menor porcentaje de sólidos totales, proteínas, grasas y calcio; mientras que el recuento total de bacterias, así como el riesgo de encontrar residuos de antibióticos se incrementan, afectando su calidad (Blowey y Edmondson, 1995). Esta leche puede constituir un peligro potencial para la salud de los consumidores (Philpot y Nickerson, 2000), y por esta razón, los centros de acopio castigan la leche de baja calidad con el rechazo o con una penalidad en el precio, generando pérdidas importantes al productor rural.

La mastitis subclínica tiene un origen multifactorial; dentro de ellos se puede mencionar el número de partos (Harmon, 2004), momento de la lactancia (De Haas et al., 2002), tamaño del establo (Skrypeck et al., 2004), estación del año (Skrypeck et al., 2004; Green et al., 2006), higiene del ordeño (Schreiner y Ruegg, 2003) y el nivel tecnológico de los establos (Ortiz y Vera, 2005). Se dispone de varios métodos para el diagnóstico a nivel de campo y de laboratorio. El Recuento de Células Somáticas (RCS) en muestras de leche es un método rápido y relativamente fácil de hacer, habiéndose convertido en un procedimiento rutinario de diagnóstico para determinar la calidad de leche en muchos países (Monardes y Barria, 1995). El mayor número de células somáticas significa un mayor grado de inflamación de la ubre y menor calidad de leche (Blowey y Edmondson, 1995).

Los objetivos del estudio fueron determinar la calidad de la leche mediante el RCS en tanques de leche de establos y asociaciones de ganaderos, en dos épocas del año, y determinar la presencia de mastitis subclínica en función del número de partos, momento de la lactancia y tamaño del establo, en la provincia de Huaura, Perú. 


\section{Materiales y Métodos}

La investigación se realizó en los distritos de Végueta y de Santa María, provincia de Huaura, región Lima-Provincias, entre agosto de 2009 a julio de 2010. Hosltein es la raza predominante de ganado bovino en la zona. Los establos grandes y medianos tienen un sistema intensivo de crianza, con alimentación a base de maíz chala (Zea mays) y alimento concentrado, y ordeño mecánico; mientras que en los establos pequeños el sistema de crianza es intensivo o semiintensivo, con alimentación a base de maíz chala, panca de maíz, pasto elefante (Pennisetum purpureum), gramalote (Axonopus affinis) y uso de concentrados en menor proporción, y el ordeño, generalmente, es manual.

La temperatura y humedad relativa promedio en el verano en la zona es de 20.3 a $20.8{ }^{\circ} \mathrm{C}$ y de 90.9 a $92.5 \%$, respectivamente, en tanto que en invierno es de 19.6 a 20.5 ${ }^{\circ} \mathrm{C}$ y de 90.2 a $92.6 \%$, respectivamente, según datos locales de la Estación Meteorológica Convencional Camay-SENAMHI.

\section{Calidad de la Leche}

Se tomaron muestras de leche de tres tanques pertenecientes a establos lecheros y de cuatro tanques de asociaciones de pequeños ganaderos. Las muestras se recolectaron en frascos de vidrio estériles, en las mañanas y una vez al mes, totalizando 70 muestras. Previo a la toma, y con la finalidad de obtener una muestra homogénea, se puso en funcionamiento las paletas del tanque para agitar la leche durante 10 minutos.

La calidad de la leche se determinó mediante el RCS, a través de un contador electrónico de partículas (Porta SCC Milk Test), de acuerdo a las indicaciones formuladas por el fabricante (Portacheck, 2011). El método tiene una alta sensibilidad en conteos elevados (Viguier et al., 2009).
Se consideró el tipo de productor (establos grandes vs. asociaciones de ganaderos), la procedencia de la leche (tanques de ganaderos individuales vs. tanques de asociaciones ganaderas), y la época del año [verano (diciembre - abril); invierno (mayo - noviembre)].

\section{Mastitis Subclínica}

La mastitis subclínica se evaluó a nivel de 32 establos lecheros con una población total de 2100 vacas. Se realizó la prueba de California Mastitis Test (CMT) a todas las vacas en producción durante el ordeño de la tarde. El procedimiento e interpretación del CMT se realizó de acuerdo a lo establecido por el US National Mastitis Council (Philpot y Nickerson, 2000).

Se consideraron las variables número de partos $(1,2,>2)$, momento de lactancia (inicio: $\leq 100$, media: 101-180, final: $\geq 180$ días), y tamaño del establo (pequeño: $\leq 25$, mediano: 26-100, grande: $\geq 100$ vacas en producción). Los grupos de tamaño de establo fueron establecidos a priori de acuerdo a las características de tenencia de la propiedad en la región (Velásquez, 2011). En el análisis de los factores número de parto y momento de la lactancia se trabajó sólo con vacas de medianos y pequeños establos.

\section{Análisis Estadístico}

En la evaluación del RCS se empleó el análisis de varianza para determinar el efecto de las variables tipo de productor, tipo de tanque y época del año. El factor tanque estuvo anidado al tipo de productor. Asimismo, los resultados del CMT se relacionaron con las variables en estudio a través de tablas de contingencia con la prueba de Chi-Cuadrado, y las diferencias entre las categorías de determinaron con la prueba de proporciones. En el análisis de los datos se utilizó el programa estadístico MINITAB v 15. 


\section{Resultados y Discusión}

Los resultados del RCS se detallan en el Cuadro 1. Se utilizó un modelo no balanceado, por lo que el análisis se basó en medias o promedios mínimo cuadráticos para predecir los resultados que se habrían producido en un modelo balanceado (Kuehl, 2001). Las medias de establos y asociaciones de ganaderos fueron estadísticamente similares, y se encuentran por encima del nivel máximo permitido (500 x $10^{3}$ células $/ \mathrm{ml}$ ) por las normas técnicas peruanas (INDECOPI, 2003). Estos valores fueron superiores al estudio de Ortiz y Vera (2005), en la cuenca lechera de Arequipa, donde encontraron promedios de $505 \times 10^{3}$ células $/ \mathrm{ml}$. En estudios realizados en países de América Latina como Brasil, Chile, Colombia y Venezuela se hallaron valores entre 206 a 730 x $10^{3}$ células/ml(Noboa, 1998; Paula et al., 2004; Faria et al., 2005).

El incremento de células somáticas en la leche se encuentra acompañado de un aumento en el porcentaje de cuartos mamarios afectados con mastitis subclínica, encontrándose que niveles por encima de $600 \times 10^{3}$ células/ml son compatibles con el 61 a $79 \%$ de mastitis subclínica en vacas en producción (Eberhart et al., 1982).

El elevado número de células somáticas encontrado en el presente estudio se debe probablemente a deficientes prácticas de manejo (Philpot y Nickerson, 2000). Estas afirmación se fortalece con observaciones previas en ganaderías lecheras del valle de Huaura (Velásquez, 2011), donde se determinó que el $83 \%$ de los productores realiza ordeño manual, $44 \%$ no efectúa el sellado de los pezones al finalizar el ordeño, 35\% no aplica antibióticos al momento del secado, $85 \%$ de los establos mantiene una higiene de regular a mala durante el ordeño, y solo el 23\% realiza la prueba de CMT regularmente.

El RCS en los meses de verano fue 73.9\% superior en comparación con los meses de invierno ( $<<0.05$, Cuadro 1$)$, similar al $12 \%$ superior observado en ganaderías leche- ras del sur del país (Ortiz y Vera, 2005) y en estudios realizados en otras latitudes (Noboa, 1998; Skrypeck et al., 2004; Green et al., 2006). El incremento de células somáticas en el verano es consecuencia del estrés calórico, que genera en el organismo animal una respuesta de inmunosupresión (Philpot y Nickerson, 2000). Esta situación se complica, además, con una mayor contaminación por el excesivo calor y exposición de patógenos en la punta de los pezones, que luego invaden el interior de la ubre y desencadenan la inflamación (Harmon, 2004).

En la evaluación de la frecuencia de mastitis subclínica, tres establos fueron clasificados en el grupo de establos grandes, cinco establos como medianos y 24 establos como pequeños. La frecuencia de mastitis subclínica por efecto del tamaño del establo, número de partos y momento de lactancia se muestra en el Cuadro 2.

La mastitis subclínica se presentó con menor frecuencia en establos pequeños $(p<0.05)$. Diversos estudios señalan, asimismo, un menor porcentaje de mastitis subclínica en establos con menos de 15 vacas (Skrypeck et al., 2004; Hamilton et al., 2006). En el valle de Huaura, el 92\% de los establos son pequeños (promedio de seis vacas), con sistemas de crianza semiintensivos (Velásquez, 2011), y bajo estas condiciones, el estrés a que son sometidos los animales en producción es inferior al de establos medianos y grandes, lo que influiría en una menor presentación de mastitis subclínica (Dobson et al., 2000).

Se encontró una mayor presentación de mastitis subclínica en vacas de dos o más partos, aunque este valor no fue estadísticamente diferente de la frecuencia encontrada en vacas de primer parto (Cuadro 2). Vacas con más de dos partos tienen mayores probabilidades de infección por su mayor tiempo de permanencia en el establo y de exposición a los patógenos (Green et al., 2006). Además, algunas infecciones se vuelven crónicas y el sistema inmunológico de las vacas adultas y de edad avanzada no 
Cuadro 1. Recuento de células somáticas (RCS/ml) en tanques de leche de establos lecheros y de asociaciones de ganaderos, durante el verano e invierno. Huaura, 2009-2010

\begin{tabular}{lcc}
\hline Factores & N. $^{\circ}$ de muestras & Recuento de células somáticas ${ }^{1}$ \\
\hline Tipo de productor & 30 & $755.4 \pm 46.9^{\mathrm{a}}$ \\
Establos & 40 & $752.1 \pm 41.1^{\mathrm{a}}$ \\
Asociaciones & 10 & $1,034.9 \pm 79.2^{\mathrm{a}}$ \\
Tanques de frío & 10 & $651.4 \pm 79.2^{\mathrm{b}}$ \\
Establo 1 & 10 & $579.2 \pm 79.2^{\mathrm{b}}$ \\
Establo 2 & & \\
Establo 3 & 10 & $826.9 \pm 79.2^{\mathrm{a}}$ \\
Asociaciones & 10 & $616.9 \pm 79.2^{\mathrm{a}}$ \\
Asociación 1 & 10 & $729.4 \pm 79.2^{\mathrm{a}}$ \\
Asociación 2 & 10 & $835.4 \pm 79.2^{\mathrm{a}}$ \\
Asociación 3 & & \\
Asociación 4 & 21 & $957.1 \pm 54.1^{\mathrm{a}}$ \\
Época del año & 49 & $550.3 \pm 35.5^{\mathrm{b}}$ \\
Verano & Invierno &
\end{tabular}

${ }^{1}$ Medias Mínimo Cuadráticas \pm error estándar, expresado en miles

${ }^{a, b}$ Superíndices diferentes dentro de factores indican diferencia significativa $(p<0.05)$

es tan eficiente como en las vacas jóvenes (Philpot y Nickerson, 2000).

Se encontró una relación de dependencia entre el momento de la lactancia y la presentación de mastitis subclínica ( $\mathrm{p}<0.05$, Cuadro 2). Estos resultados coinciden con los obtenidos por De Hass et al. (2002) y Harmon (2004). El mayor porcentaje de cuartos afectados en los estadios finales de la lactancia se debería al incremento de la cantidad normal de células somáticas que se concentran en un menor volumen de leche, por efecto de una menor producción a medida que avanza la lactancia (Harmon, 2004).

\section{Conclusiones}

- El recuento promedio de células somáticas en tanques de leche de establos y de asociaciones de ganaderos de la provincia de Huaura es elevado, y está por encima del límite máximo permitido por las normas técnicas de calidad del país.

- La frecuencia de mastitis subclínica fue mayor en establos grandes, en vacas con más de dos partos y en la etapa final de lactancia. 
Cuadro 2. Frecuencia de mastitis subclínica en vacas lecheras en producción, en relación al tamaño del establo, número de partos y momento de lactancia, en establos lecheros del valle de Huaura. 2009-2010

\begin{tabular}{|c|c|c|c|c|}
\hline \multirow{3}{*}{ Factores } & \multicolumn{4}{|c|}{ N. ${ }^{\circ}$ de cuartos mamarios } \\
\hline & \multirow{2}{*}{$\begin{array}{l}\text { Total } \\
\text { (n) }\end{array}$} & \multicolumn{3}{|c|}{ Positiv os a $\mathrm{CMT}^{1}$} \\
\hline & & $\mathrm{n}$ & $\%$ & IC $(95 \%)^{2}$ \\
\hline \multicolumn{5}{|c|}{ Tamaño del establo $^{3}$} \\
\hline Grande & 6,823 & 3,403 & $49.9^{a}$ & $48.9-50.9$ \\
\hline Mediano & 565 & 297 & $52.6^{a}$ & $48.6-56.6$ \\
\hline Pequeño & 1,006 & 299 & $29.8^{b}$ & $26.8-32.8$ \\
\hline \multicolumn{5}{|c|}{ Número de partos } \\
\hline 1 & 262 & 86 & $32.8^{a b}$ & $26.8-38.8$ \\
\hline 2 & 113 & 28 & $24.8^{a}$ & $16.8-32.8$ \\
\hline$>2$ & 248 & 101 & $40.8^{b}$ & $34.8-46.8$ \\
\hline \multicolumn{5}{|c|}{ Momento de lactancia ${ }^{4}$} \\
\hline Inicio & 220 & 51 & $23.2^{a}$ & $17.2-29.2$ \\
\hline Medio & 199 & 76 & $38.2^{b}$ & $31.2-46.2$ \\
\hline Final & 238 & 96 & $40.3^{b}$ & $34.3-46.3$ \\
\hline
\end{tabular}

\section{LITERATURA CitADA}

1. Blowey R, Edmondson P. 1995. Control de la mastitis en granjas de vacunos de leche. Zaragoza: Acribia. 208 p.

2. De Haas Y, Barkema HW, Veerkamp $\boldsymbol{R} \boldsymbol{F}$. 2002. The effect of pathogenspecific clinical mastitis on the lactation curve for somatic cell count. J Dairy Sci 85: 1314-1323.

3. Dobson H, Tebble JE, Smith RF, Ward WR. 2000. Is stress really all that important? Theriogenology 55: 65-73.
4. Eberhart RJ, Hutchinson LJ, Spencer SB. 1982. Relationships of bulk tank somatic cell counts to prevalence of intramammary infection and to indices of herd production. J Food Protect 45: 1126- 1129.

5. Faria JF, García UA, D’Pool G, Kutchinskaya VL, Allara CM, Angelosante G. 2005. Detección de mastitis subclínica en bovinos mestizos doble propósito ordeñados en forma manual o mecánica. Comparación de tres pruebas diagnósticas. Rev Científica FCV-LUZ 15(2): 109-118. 
6. Green MJ, Bradley AJ, Newtonb $H$, Browne WJ .2006. Seasonal variation of bulk milk somatic cell counts in UK dairy herds. Prev Vet Med 74: 293-308.

7. Harmon RJ. 2004. Physiology of mastitis and factors affecting somatic cell counts. Dairy Sci 77: 2103-2112.

8. Hamilton C, Emmanuelson $U$, Forslund K, Hansson I, Ekman T. 2006. Mastitis and related management factors in certified organic dairy herds in Sweden. Act Vet Scand 48: 11. [Internet]. Available in: http:// www.actavetscand.com/content/48/1/11

9. INDECOPI. 2003. Norma Técnica Peruana 2002.001: 2003. Leche y productos lácteos. Leche cruda. $4^{\circ}$ ed. Lima. INDECOPI. $9 \mathrm{p}$.

10. Kuehl R. 2001. Diseño de experimentos. $2^{\circ}$ ed. México: Ed ThomsonLearning. p 212-215.

11. Ministerio de Agricultura. 2010. Dinámica agropecuaria 1997-2009. [Internet], [12 mayo 2011]. Disponible en: www.minag.gob.pe/download/pdf/ especiales/dinamica/IV_Pecuario.pdf

12. Monardes H, Barria N. 1995. Recuento de células somáticas y mastitis. Tecnovet, [Internet], [12 mayo 2006]. Disponible en: http://www.tecnovet.uchile.cl/CDA/tecno-vet_articulo/ 0,1409 , S C I D \% 2 - 53 D 85 - $19 \%$ 2526ISID\%253D427,00.html

13. Noboa J. 1998. Calidad sanitaria y composición nutricional de leche de estanque en predios de la provincia de Valdivia, durante el periodo primavera-verano. Tesis de Médico Veterinario. Valdivia: Univ. Austral de Chile. [Internet], [20 mayo 2011]. Disponible en: http:// cybertesis.uach.cl/tesis/uach/1998/ fvn744c/doc/fvn744c.pdf
14. Ortiz ZC, Vera AR. 2006. Recuento de células somáticas en hatos lecheros de diferente nivel tecnológico en Arequipa. Rev Inv Vet, Perú 17(2): 104-107.

15. Orrego J, Delgado A, Echevarría L. 2003. Vida productiva y principales causas de descarte de vacas lecheras Holstein en la cuenca de Lima. Rev Inv Vet, Perú 14(1): 68-73.

16. Paula MC, Ribas NP, Monardes HG Arce JE, Andrade UV. 2004. Contagem de células somáticas em amostras de leite. R Bras Zootec 33: 1303-1308.

17. Philpot W, Nickerson S. 2000. Ganando la lucha contra la mastitis. Naperville, IL, USA: Wesfalia Surge. 192 p.

18. Portacheck. 2011. El porta SCC quick test. [Internet], [5 de enero 2011]. Disponible en: http://www.portacheck.com/ portascc.php

19. Rodríguez AC, Caraviello DZ, Ruegg PL. 2005. Management of Wisconsin dairy herds enrolled in milk quality teams. J Dairy Sci 88: 2660-2671.

20. Schreiner DA, Ruegg PL. 2003. Relationship between udder and leg hygiene scores and subclinical mastitis. J Dairy Sci 86: 3460-3465.

21. Skrypeck R, Wojtkowski J, Fahr RD. 2004. Factors affecting somatic cell count in cow bulk tank milk- a case study from Poland. J Vet Med A Physiol Pathol Clin Med 51(3): 127-131.

22. Velásquez CR. 2011. Factores de riesgo asociados a la producción de leche de calidad en el valle de Huaura. Tesis Doctoral. Lima: Univ Nac Federico Villarreal. $74 \mathrm{p}$.

23. Viguier C, Arora S, Gilmartin N, Welbeck K, O'Kennedy, R. 2009. Mastitis detection: current trends and future perspectives. Trends Biotechnol 27: 486-493. 